NASA Technical Memorandum 88914

\title{
The Survivability of Large Space-Borne Reflectors Under Atomic Oxygen and Micrometeoroid Impact
}

Daniel A. Gulino

Lewis Research Center

Cleveland, Ohio

Prepared for the

25th Aerospace Sciences Meeting

sponsored by the American Institute of Aeronautics and Astronautics Reno, Nevada, January 12-15, 1987

\section{Mnsh}


Trade names or manufacturers' names are used in this report for identification only. This usage does not constitute an official endorsement, either expressed or implied, by the National Aeronautics and Space Administration. 
THE SURVIVABILITY OF LARGE SPACE-BORNE REFLECTORS UNDER ATOMIC

\title{
OXYGEN AND MICROMETEOROID IMPACT
}

\author{
Daniel A. Gulino \\ National Aeronautics and Space Administration \\ Lewis Research Center \\ Cleveland, Ohio 44135
}

\begin{abstract}
SUMMARY
Solar dynamic power system mirrors for use on Space Station and other spacecraft flown in low earth orbit (LEO) are exposed to the harshness of the LEO environment. Both atomic oxygen and micrometeoroids/space debris can degrade the performance of such mirrors. Protective coatings will be required to protect oxidizable reflecting media, such as silver and aluminum, from atomic oxygen attack. Several protective coating materials have been identifled as good candidates for use in this application. The durability of these coating/mirror systems after pinhole defects have been inflicted during their fabrication and deployment or through micrometeoroid/space debris impact once on-orbit is of concern. Studies of the effect of an oxyonen $n$ ? asma environment on protected mirror surfaces with intentionally induced pinhole defects have been conducted at NASA Lewis and are reviewed in this paper. It has been found that oxidation of the reflective layer and/or the substrate in areas adjacent to a pinhole defect, but not directly exposed by the pinhole, can occur.

\section{ELECTRIC POWER GENERATION ON SPACE STATION}

Electric power generation on the Space Station is planned to be accomplished by two means: traditional photovoltaic panels will account for about one-third of the total power generated, and solar dynamic modules wtll account for the other two-thirds. Solar dynamic systems generate electricity by focusing the sun's radiation, either by reflecting mirrors or refracting lenses, onto the receiver of a heat engine. The current configuration calls for a reflective system, with either aluminum or silver as the reflective medium (ref. 1).
\end{abstract}

Figure 1 is a schematic diagram of a solar concentrator which utilizes a mirror made up of 19 hexagonal elements which are in turn made up of 24 triangular, spherically contoured facets. Figure 2 is a diagram of one of the triangular facets. One proposal calls for these facets to consist of an aluminum honeycomb core with a graphite-epoxy laminate on each side. The reflective metal (most likely either aluminum or silver) is deposited onto the graphite-epoxy, followed then by the protective coating. This paper is concerned with the potential effects of the low earth orbit environment on the performance of these mirrors.

\section{THE LOW EARTH ORBIT ENVIRONMENT}

The low earth orbit (LEO) environment presents several hazards to the long term survivability of large mirrors. The dominant chemical constituent between 200 and $650 \mathrm{~km}$ is atomic oxygen ( $\mathrm{fig}$. 3) (ref. 2), and, since both aluminum and silver are susceptible to oxidation, protection of the reflective metal from atomic oxygen attack is vital to the survivability of these mirrors. 
Another potential hazard to space-borne reflectors in LEO is the particulate matter environment. Micrometeoroids, as well as other such "natural" phenomena as space debris, are a potential source of pinhole defects in the protective coating of a reflecting mirror. Other potential sources of such defects include the fabrication, handling, transport, and deployment of the mirror facets. Once a pinhole defect has been inflicted, by whatever mecha$\mathrm{nism}$, a pathway is provided for direct attack of the reflective layer and/or the graphite-epoxy substrate by atomic oxygen.

\section{CANDIDATE PROTECTIVE COATINGS}

Several materials have been proposed for use as protective coatings over the reflective layer. Any material chosen for such an application must meet a number of requirements. The material must be transparent to solar radiation in the wavelength region of interest, generally 200 to $2500 \mathrm{~nm}$. It must also be easily applied, strongly adherent, have low toxicity, and be of low cost. Finally, of course, it must be resistant to atomic oxygen. Materials proposed for such use include several metal oxides, such as aluminum oxide, silicon oxide, and indium-tin oxide. Other materials under consideration include magnesium fluoride and silicon nitride. This paper will discuss some of the experiments that have been conducted at NASA Lewis to determine the effectiveness of these coating materiais in both the presence of and absence of intentionally introduced pinhole defects.

\section{EXPERIMENTAL ASPECTS}

The sample mirrors studied were prepared both at NASA Lewis and at Harris Corporation. The NASA Lewis samples were prepared on a variety of substrate materials, including aluminum, electro-formed nickel, beryllium-copper alloy, graphite-epoxy composite, and fused silica. They were fabricated by ion beam sputtering of targets of the various protective coatings in a deposition system described elsewhere (ref. 3). The Harris samples were prepared on both glass and graphite-epoxy substrates. The protective coatings were deposited by both ion beam sputtering and vacuum evaporation.

The atomic oxygen environment was simulated with a Structure Probe, Inc. Plasma Prep II plasma asher. This device generates a plasma by $13.56 \mathrm{MHz}$ RF excitation of the carrier gas, which in all cases was ambient alr. While such information does exist for a handful of materials, direct comparisons between lifetime in the asher and lifetime in LEO are difficult; however, the asher is very useful for making gross determinations of the likelihood of survivability of a particular material in LEO.

Pinhole defects were induced in protective coatings with an S.S. White Airbrasive high-speed abrasive particle system. This unit accelerated the particles, 27 mm diameter alumina in this case, to a calculated velocity of approximately $340 \mathrm{~m} / \mathrm{sec}$ at a flux of approximately $6 \times 1012 \mathrm{~cm}^{-2} \mathrm{sec}^{-1}$. This differs from the actual, LEO micrometeoroid environment in at least two important respects. First, particle velocities are considerably higher in LEO, being on the order of 10 to $60 \mathrm{~km} / \mathrm{sec}$ (refs. 4 and 5). The effect of particle impact at velocities of this magnitude are very different. Second, micrometeoroids impacting at these velocities have been shown to become briefly fluid-like in their behavior for a short time after impact. The result is that the particle can actually line the interior of the impact crater (refs. 5 
and 6). Thus, self-protection of the underlying material from atomic oxygen exposure as a result of the micrometeoroid itself is possible. The significance of the present experiments thus lies more in the atomic oxygen exposure response of pinhole defects (from whatever source), than in accurate micrometeoroid simulation.

A11 reflectances reported herein were measured on a Perkin-Elmer Lambda-9 UV/VIS/NIR spectrophotometer equipped with a $60 \mathrm{~mm}$ diameter, barium sulfatecoated integrating sphere. Integrated solar reflectances were measured by obtaining the spectral reflectance over the wavelength range of 200 to $2500 \mathrm{~nm}$ and then convoluting this into the AMO solar spectrum over the same wavelength range. Both specular and total reflectances were obtained, the former of which was measured at an acceptance aperture solid angle of $0.096 \mathrm{sr}$.

\section{DISCUSSION}

\section{Defect-free Samples}

The effect of the asher plasma environment on the specular solar reflectance of several reflector/substrate systems is shown in figure 4. For comparison, the effects on an unprotected silver surface and an unprotected aluminum surface are also shown. Clearly, silver requires protection. (There is no apparent effect of substrate.) Any of the protective coatings displayed in figure 4 would appear to be satisfactory. While the unprotected aluminum sample continued to have a high specular reflectance, and hence would not appear to require protection, there is concern (ref. 7 ) that the self-generated oxide layer which protects the aluminum surface would not be satisfactory. Specifically, the physical structure of aluminum oxide is such that neutral atomic oxygen could diffuse through it and continue to oxidize the aluminum surface. Thus the oxide thickness would continuously increase, resulting in a gradual, but steady, decline in specular reflectance. It is perhaps safer and wiser to intentionaliy apply a coating of known thickness and properties under controlled conditions, rather than rely on the natural growth of an oxide with uncertain properties.

Tables I and II summarize some of the experimental results that have been obtained on the effect of the asher plasma on various protective coating/ reflective layer/substrate combinations. For comparison purposes, a quantity defined as the fractional loss of reflectance per unit asher exposure time was developed as a way of comparing the relative degree of protection afforded the reflecting layer by the various protective coatings. While this quantity is based only on the start and end values of reflectance, it does give qualitatively useful information.

Samples with Pinhole Defects

Figures 5 through 13 present results showing the effect of pinhole defects on the asher plasma environment durablitity of both silver and aluminum reflecting surfaces with protective coatings on both graphite-epoxy composite and fused quartz substrates. The protective coatings for most of the samples consisted of $700 \AA$ of $\mathrm{Al}_{2} \mathrm{O}_{3}$ followed by 2200 of $\mathrm{SiO}_{2}$. The generally observed effect is that oxidation of the reflective layer and/or the substrate occurs in undamaged areas surrounding a defect site. 
In the case of mirror samples constructed on oxidizable (graphite-epoxy) substrates, oxidation of both the reflecting layer and the substrate surrounding the defect occurs. Figure 5 shows a silver mirror surface with intentionaliy induced pinhole defects. A number of the defect sites are visible. Figure 6 shows a similar surface after $90 \mathrm{hr}$ of exposure in the plasma asher. Several of the defect sites are now surrounded by a discolored, (in this case, darkened) border. These discolored areas are the result of oxidation of the silver and/or the graphite-epoxy substrate in the area surrounding the defect site. Figure 7 shows a similar effect, but through an elongated defect.

Figure 8 shows an eroded surface after approximately $240 \mathrm{hr}$ of plasma asher exposure (about $240 \mathrm{hr}$ ). Oxidative undercutting occurred to a large extent in this sample. The discolorations now cover a substantial portion of the total sample surface area. Figure 9 shows the lower right portion of figure 8 , but at a higher magnification and a higher $\left(60^{\circ}\right)$ angle of $t i 1 t$. It can be seen that wherever there are discolorations, the surface of the coating had become distorted (caved in). This is most likely the result of the intrinsic compressive stress in the film being released by the loss of substrate.

Sample mirrors constructed on fused silica substrates showed different but related oxidative behavior. Figure 10 depicts a silver reflector sample on a fused silica substrate after about $90 \mathrm{hr}$ of plasma asher exposure. Here can be seen a light colored, puffed material protruding through almost every defect site. This material is oxidized silver expanding in the only direction available, which is through the defect opening. Unlike graphite-epoxy, fused silica does not oxidize in the asher environment. Hence, no space is created beneath the coating by oxidation of the substrate. Figure 11 shows the same surface as seen in Figure 10, but at a $60^{\circ}$ angle of tilt. Here, the extent of growth of the oxide through the opening is more easily appreciated.

Figure 12 shows a surface similar to that of Figure 10, but after approximately $240 \mathrm{hr}$ of exposure. Silver oxide protruding through the defect is again clearly seen. In addition, oxidative undercutting (perhaps more descriptively referred to as "transverse oxidation") of the silver layer beneath the protective coating is seen, as in figure 6 , as a discolored (in this case, lighter) border surrounding the defect. The extent of this undercutting is not, however, as great as on the graphite-epoxy substrate samples.

Clearly, a protective coating cannot continue to protect indefinitely after pinhole defects have been introduced. oxidative damage goes beyond what would normally be expected to occur as a result of the presence of the pinholes themselves. As pointed out earlier, there is a difference between how the pinhole defects were produced in these samples (low velocity impact by particles of constant size and composition) and the actual resuit of a micrometeoroid impact in LEO (where the particles are of many different sizes (ref. 8) and of varying composition). Also, as stated earlier, self-protection is possible.

In light of these differences, the usefulness of the results discussed here is primarily in the effect of pinhole defects on the continued atomic oxygen durability of protected mirror surfaces. Other possibie sources of pinholes exist, and these include the fabrication, transport, and deployment of large mirrors, as well as space debris. Figure 13 11lustrates this point. It shows an aluminum reflector on a graphite-epoxy substrate with a MgF 2 protective coating after about $270 \mathrm{hr}$ of exposure. The defect shown was not inten- 
tionally induced, but was present simply as a result of the fabrication and handling of the sample. It is clear that oxidation of the substrate surrounding the defect has occurred.

Figure 14 is a schematic diagram showing both the oxidative undercutting and the related, transverse oxidation processes discussed above. Figure 14(a) depicts oxidative undercutting. Here, the atomic oxygen passes through the defect site and erodes both the reflective layer and the substrate around the opening. This process apparently leaves sufficient space for the growing, expanding oxide, as none was seen protruding through the defect sites in the graphite-epoxy substrate samples. Figure 14(b) depicts transverse oxidation. Here, the atomic oxygen passes through the defect site and oxidizes only the silver reflective layer. Since in this case the substrate is not oxidizable, the expanding silver oxide has no place to go but out through the defect. It would also be expected that the rate of transverse oxidation would be slower than that of oxidative undercutting, since the protruding oxide would tend to hinder the diffusion of the atomic oxygen to the oxidation front between the oxidized and elemental silver. This slower rate was observed in the relative sizes of the discolored borders (discussed above) between the graphite-epoxy (larger border) and fused silica (smaller border) substrate samples.

\section{CONCLUSIONS}

In this paper, an attempt has been made to indicate the effects of a LEO environment on the durability of space-borne reflecting mirrors. Atomic oxygen presents a hazard to sliver and aluminum solar dynamic power system reflectors. Therefore, protective coatings are necessary to prevent atomic oxygen degradation of these metals. Several suitable candidates have been identified and discussed here. Pinhole defects, resulting from a variety of possible causes, are pathways for direct atomic oxygen attack of both the reflective metal and the substrate. It has been found that atomic oxygen degradation is not confined to that portion of the reflector surface directly exposed as a result of the presence of the pinhole. Oxidation of the reflecting layer and/or the substrate can occur. The effect of this process on the long-term, on-orbit performance of large mirrors needs to be determined.

\section{REFERENCES}

1. "Solar Concentrator Advanced Development Program, Task 1 Final Report." Harris Corp., Melbourne, FL, June 1986, (NASA CR-179489).

2. Peplinski, D.R., Arnold, G.S., and Borson, E.M., "Introduction to Simulation of Upper Atmosphere Oxygen Satellite Exposed to Atomic Oxygen in Low Earth Orbit," 13th Space Simulation Conference, NASA CP-2340, 1984, pp. 133-145.

3. Gulino, D.A., "Ion Beam Sputter Deposited Zinc Telluride Flims," Journal of Vacuum Science and Technology, Vol. 4, No. 3, Pt. 1, May/June 1986. pp. 509-513. 
4. Mirtich, M.J. and Mark, H., "Alteration of Surface Optical Properties by High-Speed Micron-Size Particles," Symposium on Thermal Radiation of

Solids, NASA SP-55, S. Katzoff, ed., 1964, Pp. 473-481.

5. Merri1, R.B. "The Effects of Micrometeroids on the Emittance of Solids," Symposium on Thermal Radiation of Solids, NASA SP-55, S. Katzoff, ed., 1964, pp. 453-472.

6. Mirtich, M.J. and Mark, H., "The Effect of Hypervelocity Projectile Material on the Uitimate Reflectance of Bombarded Polished Metals". NASA TM X-52981, 1971.

7. "Conceptual Design and Analys is of a Reflective Surface and Substrate, Vol. II - Study Results," Acurex Corp., Mountain View, CA, FR-85-168/EE, Dec. 1985.

8. Smith, R.E. and West, G.S., "Space and Planetary Environment Criteria Guidelines for Use in Space Vehical Development," Vol. 1, 1982 Revision, NASA TM-82478, 1983. 
TABLE I. - CHANGE IN INTEGRATED SOLAR REFLECTANCE OF SILVER MIRROR SAMPLES WITH VARIOUS PROTECTIVE COATINGS DEPOSITED ON VARIOUS SUBSTRATE MATERIALS

\begin{tabular}{|c|c|c|c|c|c|}
\hline \multirow[t]{2}{*}{ Substrate } & \multirow[t]{2}{*}{$\begin{array}{l}\text { Protective } \\
\text { coating }\end{array}$} & \multirow{2}{*}{$\begin{array}{c}\text { Asher } \\
\text { exposure } \\
\text { time, } \\
\text { hr }\end{array}$} & \multicolumn{2}{|c|}{$\begin{array}{l}\text { Solar specular } \\
\text { reflectance }\end{array}$} & \multirow{2}{*}{$\begin{array}{l}\text { Fractional } \\
\text { loss of } \\
\text { solar specular } \\
\text { ref lectance } \\
\text { per } 1000 \mathrm{hr}\end{array}$} \\
\hline & & & Start & Finish & \\
\hline Nickei & -...-...-- & 2.1 & 0.952 & 0.654 & 142 \\
\hline Nicke 1 & ${ }^{\mathrm{a}} \mathrm{Al}_{2} \mathrm{O}_{3}$ & 75 & .911 & .911 & 0 \\
\hline Nickel & ${ }^{\mathrm{a}} \mathrm{Si}_{3}{ }_{3} \mathrm{~N}_{4}$ & 400 & .916 & .881 & .088 \\
\hline Glass & & 634 & .972 & .937 & .055 \\
\hline Glass & ${ }^{a} \mathrm{SiO}_{2}{ }^{\prime}{ }^{b} \mathrm{MgF}_{2}$ & 634 & .970 & .927 & .068 \\
\hline Glass & ${ }^{\mathrm{a}}$ ITO & 225 & .899 & .908 & ----- \\
\hline Glass & ${ }^{a} \mathrm{ITO} \mathrm{b}_{\mathrm{MgF}_{2}}$ & 225 & .925 & .902 & .102 \\
\hline Glass & PTFE $-{ }^{\mathrm{d}} \mathrm{SiO}_{2}$ & 159 & .971 & .951 & .126 \\
\hline Gr/Epoxy & ${ }^{\mathrm{a}} \mathrm{SiO}_{2}$ & 180 & .945 & .910 & .194 \\
\hline Gr/Epoxy & $\mathrm{b}_{\mathrm{MgF}_{2}}$ & 180 & .930 & .925 & .028 \\
\hline $\mathrm{Be} / \mathrm{Cu}$ alloy & ${ }^{\mathrm{a}} \mathrm{SHO}_{2}$ & 62 & .974 & .859 & .887 \\
\hline
\end{tabular}

acoatings deposited by ion beam sputtering.

bcoatings deposited by vacuum evaporation. 
TABLE II. - CHANGE IN INTEGRATED SOLAR REFLECTANCE OF ALUMINUM MIRROR SAMPLES WITH VARIOUS PROTECTIVE COATINGS DEPOSITED ON VARIOUS SUBSTRATE MATERIALS

\begin{tabular}{|c|c|c|c|c|c|}
\hline \multirow[t]{2}{*}{ Substrate } & \multirow[t]{2}{*}{$\begin{array}{l}\text { Protective } \\
\text { coating }\end{array}$} & \multirow{2}{*}{$\begin{array}{c}\text { Asher } \\
\text { exposure } \\
\text { time, } \\
\text { hr }\end{array}$} & \multicolumn{2}{|c|}{$\begin{array}{l}\text { Solar specular } \\
\text { reflectance }\end{array}$} & \multirow{2}{*}{$\begin{array}{l}\text { Fractional } \\
\text { loss of } \\
\text { solar specular } \\
\text { reflectance } \\
\text { per } 1000 \mathrm{hr}\end{array}$} \\
\hline & & & Start & Finish & \\
\hline Glass & - & 150 & 0.976 & 0.931 & 0.300 \\
\hline Glass & $\mathrm{b}_{\mathrm{MgF}_{2}}$ & 150 & .927 & .927 & 0 \\
\hline Glass & ${ }^{a} \mathrm{SiO}_{2}$ & 634 & .897 & .879 & .019 \\
\hline Glass & $\mathrm{SiO} /^{\mathrm{b}} \mathrm{MgF}_{2}$ & 634 & .882 & .834 & .076 \\
\hline Glass & ${ }^{a}$ ITO & 225 & .850 & .844 & .027 \\
\hline Glass & $a_{1 T O} /{ }^{\mathrm{MgF}_{2}}$ & 225 & .847 & .815 & .142 \\
\hline Gr/Epoxy & ${ }^{b_{M g F}}{ }_{2}$ & 180 & .925 & .910 & .083 \\
\hline
\end{tabular}

${ }^{a}$ Coatings deposited by fon beam sputtering.

bcoatings deposited by vacuum evaporation. 


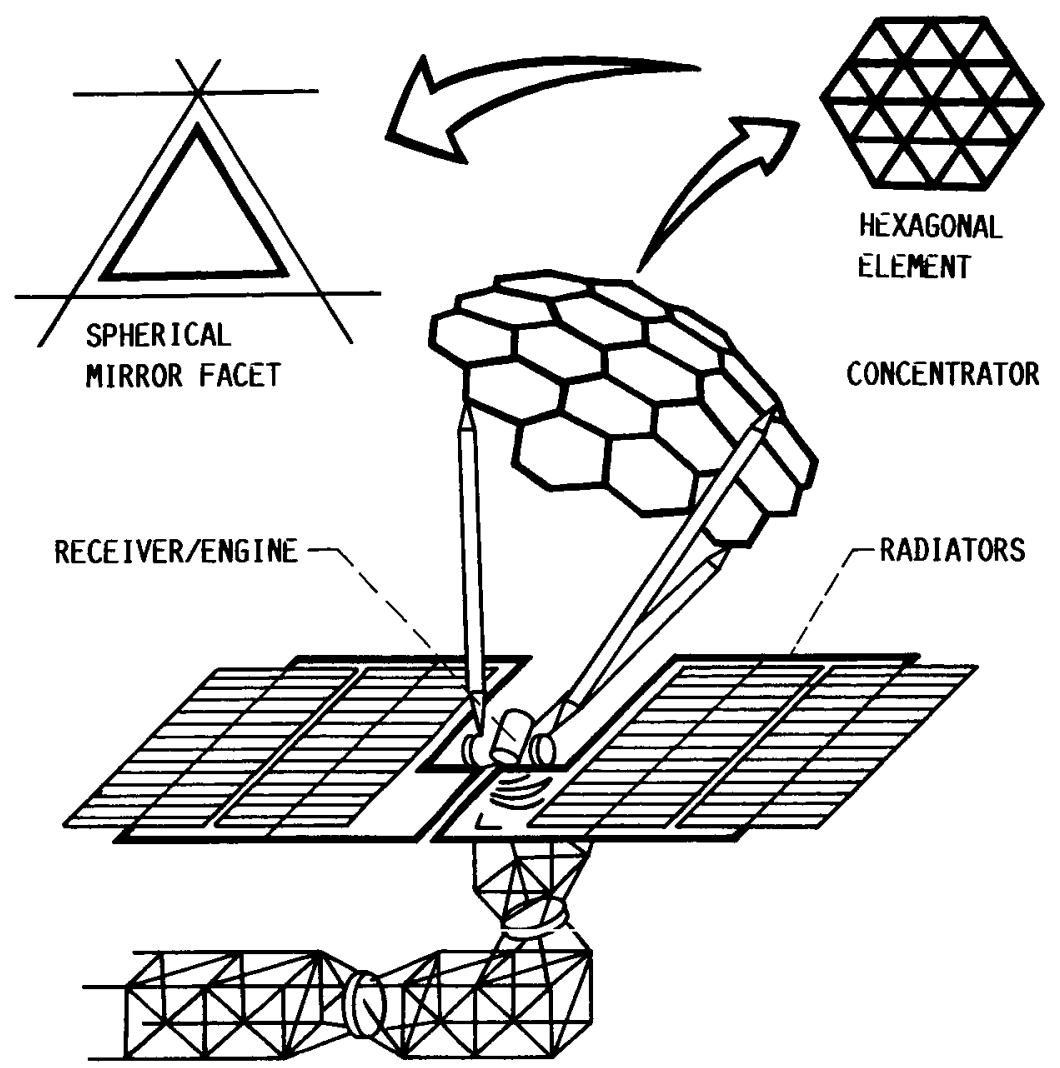

FIGURE 1.- SCHEMATIC DIAGRAM OF A SOLAR DYNAMIC MODULE WHICH INCLUDES A CONCENTRATOR MADE UP OF HEXAGONAL ELEMENTS, EACH OF WHICH IS COMPRISED OF SPHERICALLY CONTOURED TRIANGULAR FACETS.

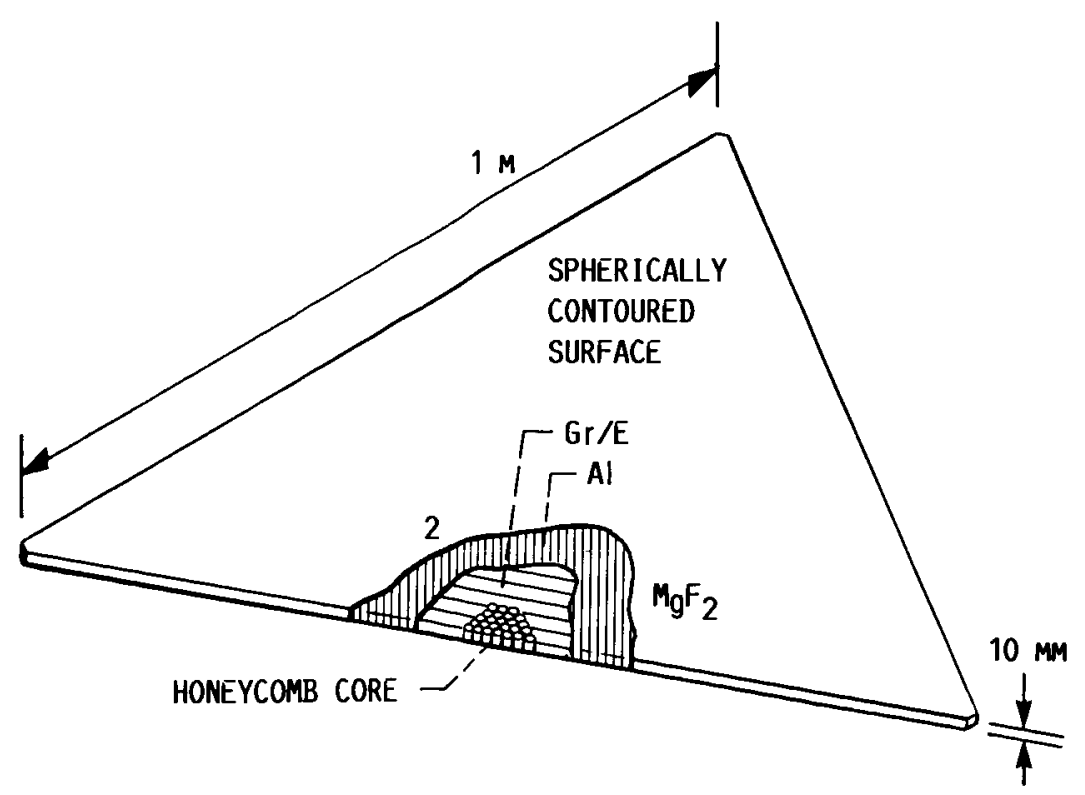

FIGURE 2. - DIAGRAM SHOWING ONE PROPOSAL FOR THE COMPOSITION OF AN INDIVIDUAL FACET. 


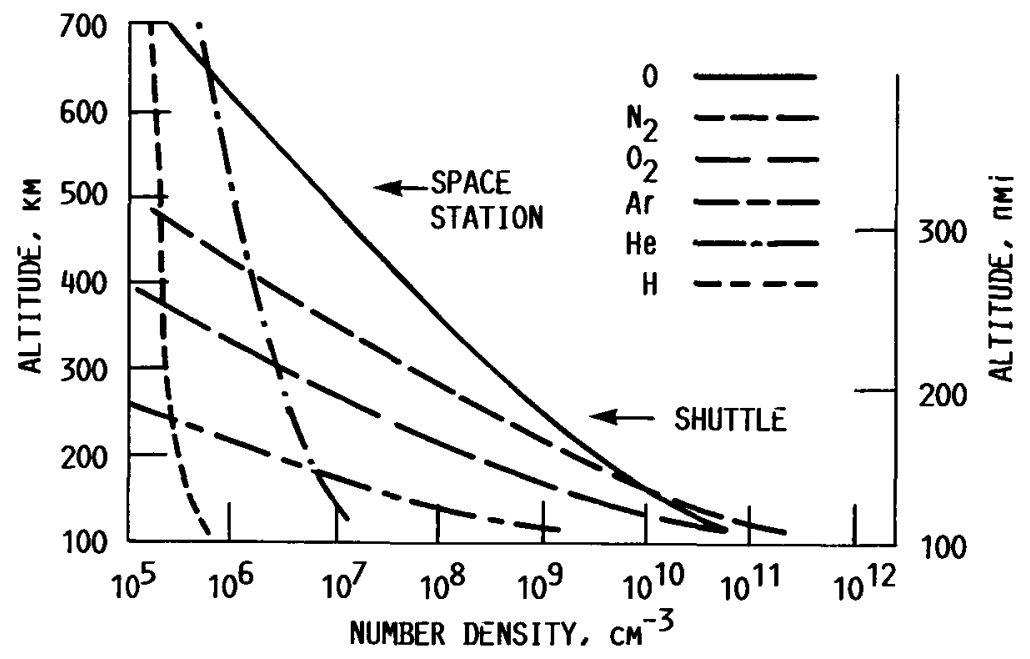

FIGURE 3.- ATMOSPHERIC COMPOSITION AS A FUNCTION OF ALTITUDE. THE TYPICAL SHUTTLE ORBIT AND PROPOSED SPACE STATION ORBIT ARE SHOWN.

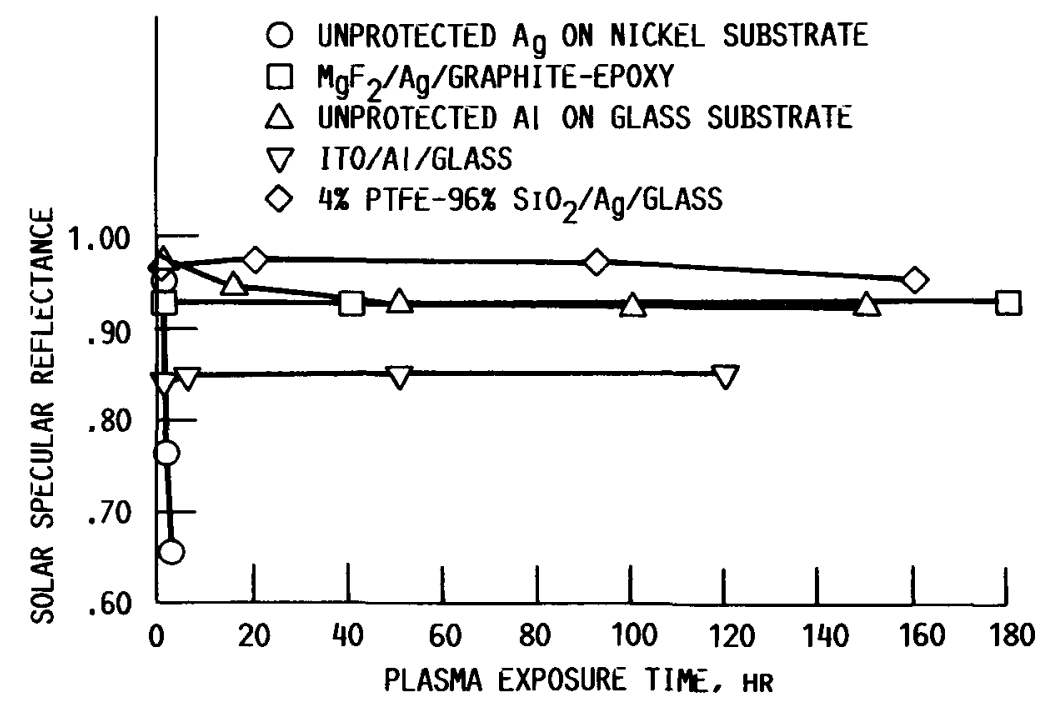

FIGURE 4.- INTEGRATED SOLAR SPECULAR REFLECTANCE AS A FUNCTION OF PLASMA EXPOSURE TIME FOR SEVERAL REFLECTOR SYSTEMS. 


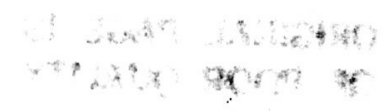

ORIGINAL PAEE IS Or POOR QUALTY

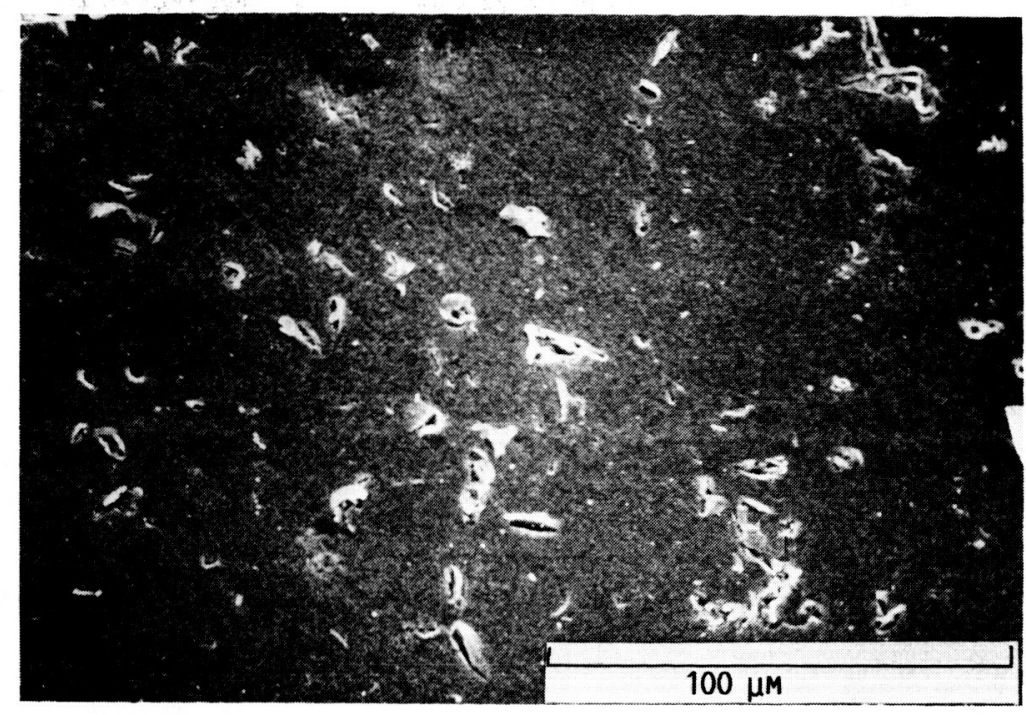

Figure 5. - Micrograph showing defects due to particle erosion. The

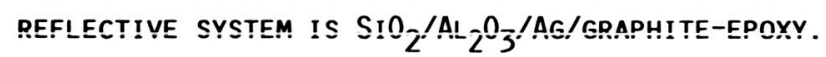

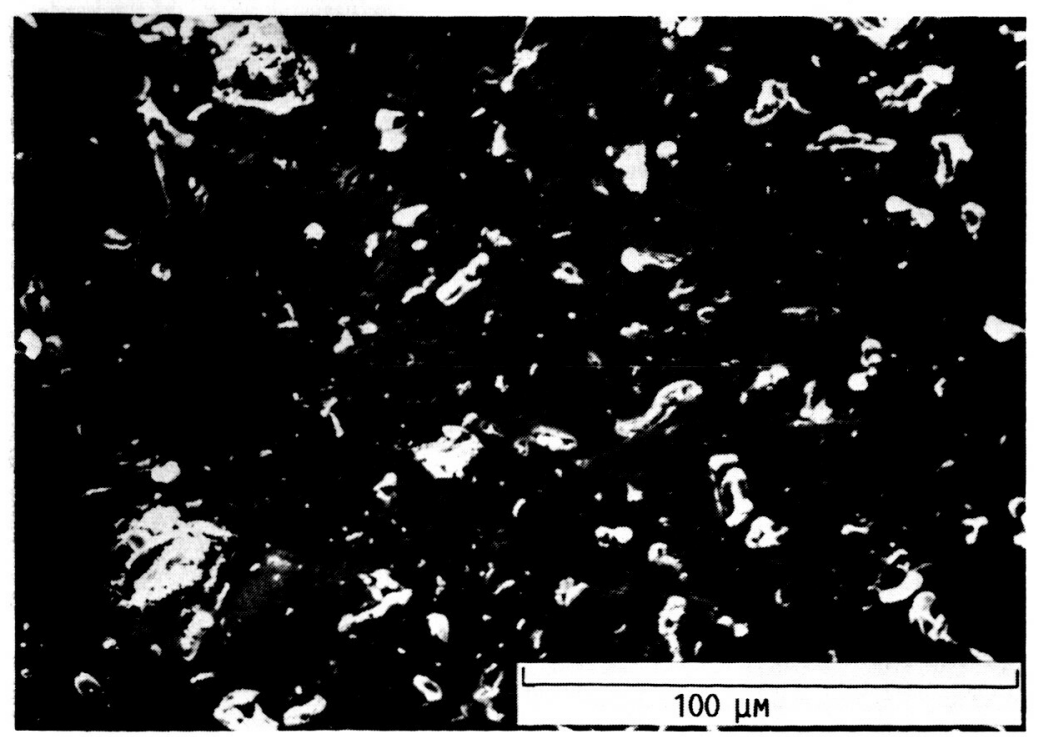

Figure 6. - Micrograph showing the particle eroded surface of a A SAMPLE IDENTICAL TO THAT OF FIGURE 5 AFTER 90 HOURS OF PLASMA ASHER EXPOSURE. SEVERAL DEFECT SITES ARE SURROUNDED BY DisColored BORDERS, WHICH INDICATE OXIDATION BENEATH THE PROTECTIVE COATING. 


\section{ORIENAL PAEE is c. poon Qunum}

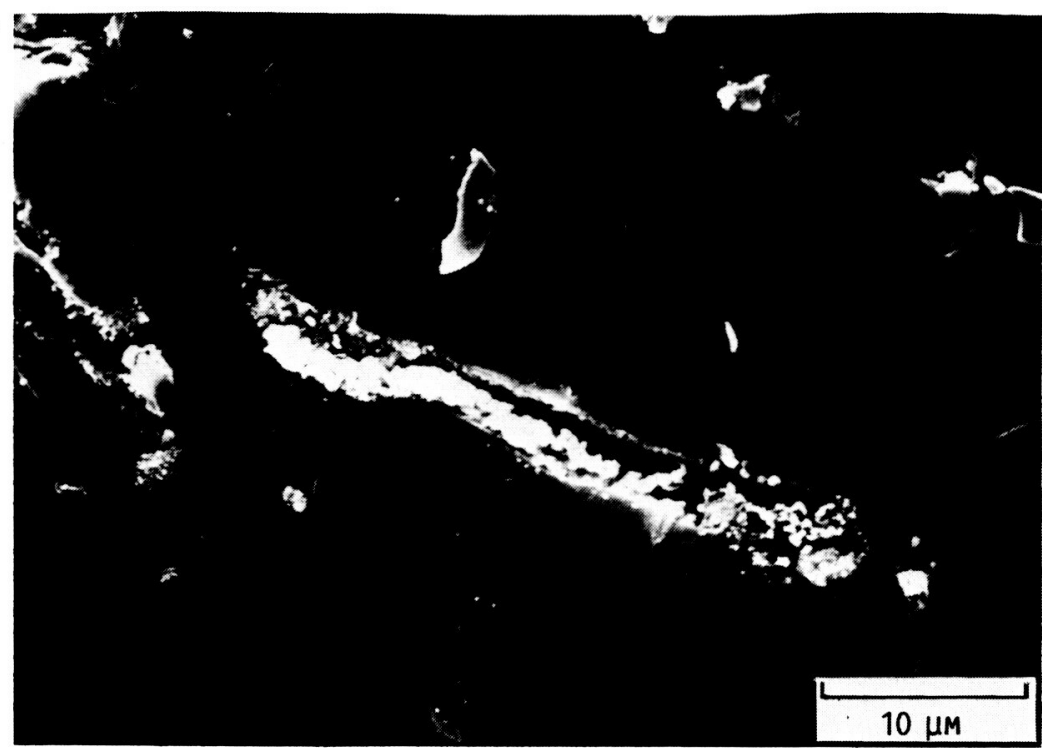

Figure 7. - Micrograph OF THE SURFACE OF A SAMPLE IDENTICAL TO THAT OF FIGURE 5 AFTER 90 HOURS OF PLASMA ASHER EXPOSURE. OXIDATIVE UNDERCUTTING AROUND THE ELONGATED DEFECT IS CLEARLY VISIBLE.

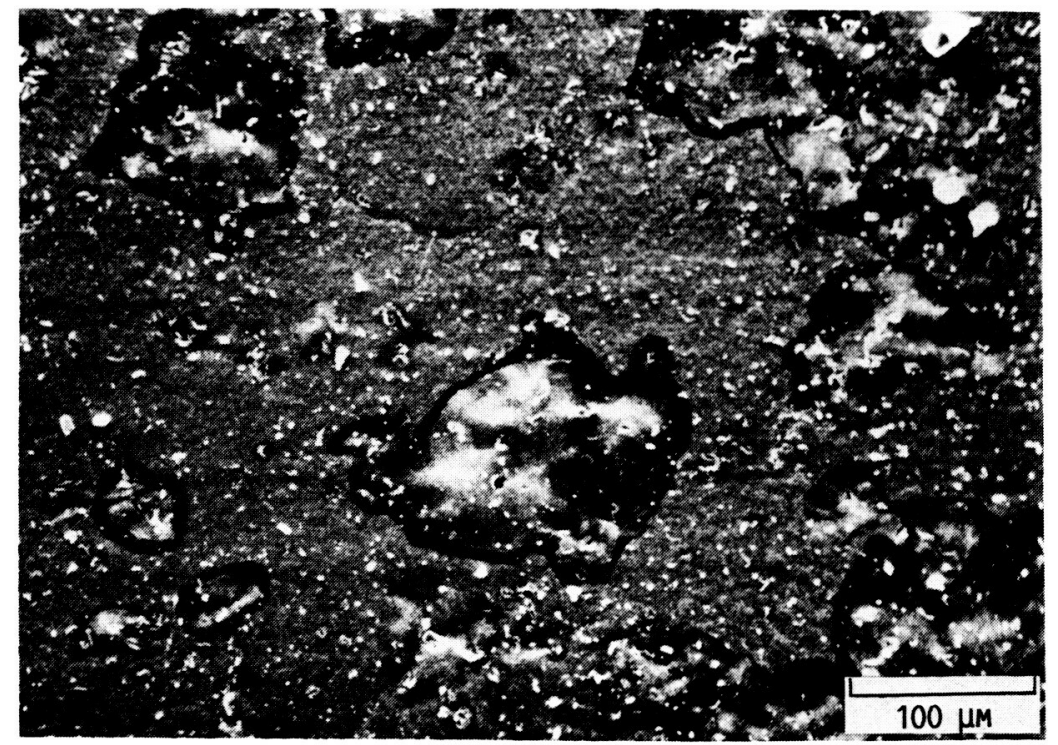

Figure 8. - Micrograph SHOWing the PARTICLE ERODED SURFACE OF a SAMPLE IDENTICAL TO THAT OF FIGURE 5 AFTER 240 HOURS OF PLASMA ASHER EXPOSURE. OXIDATIVE UNDERCUTTING HAS OCCURRED TO A LARGE EXTENT. 


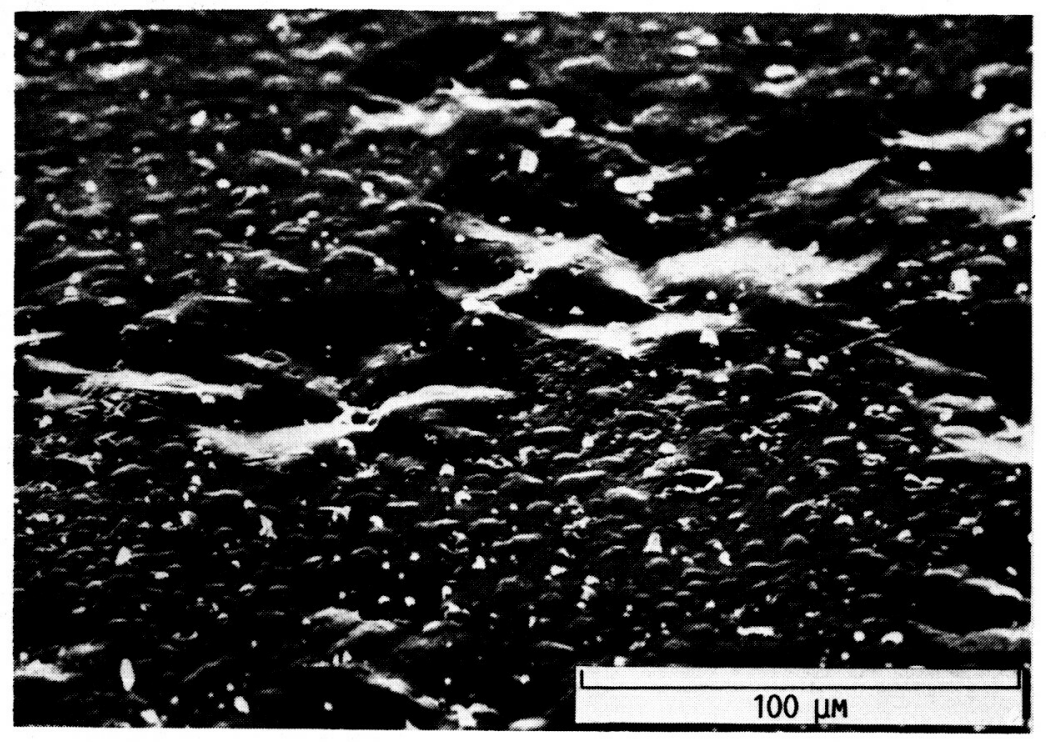

FIgURE 9. - MICROgRAPH OF THE LOWER RIGHT PORTION OF FIGURE 8 TAKEN AT A HIGH TILT ANGLE (600). WHEREVER OXIDATIVE UNDERCUTTING HAS OCCURRED, THE SURFACE HAD BECOME DISTORTED.

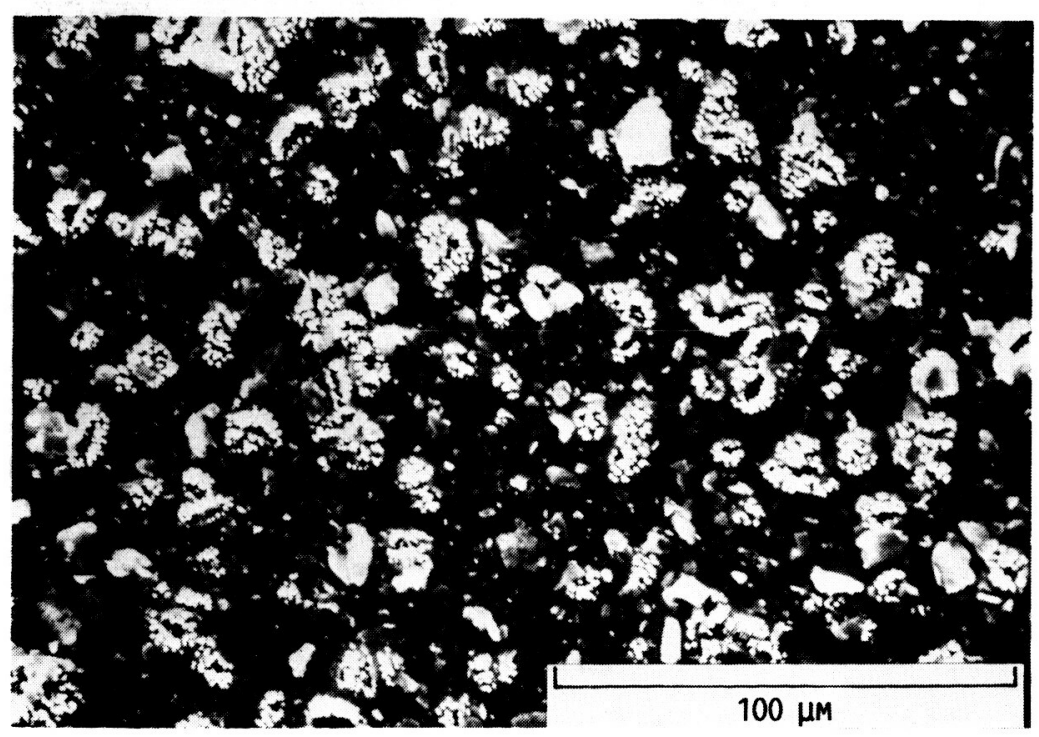

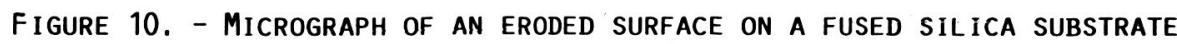
AFTER 50 HOURS OF PLASMA ASHER EXPOSURE. THE PROTECTIVE COATING IS $\mathrm{SIO}_{2} / \mathrm{AL}_{2} \mathrm{O}_{3}$. OXIDIZED SILVER PROTRUDING THROUGH THE DEFECT SITES CAN BE SEEN. 


\section{ORIGINAL PAGE IS O. POOR quartr}

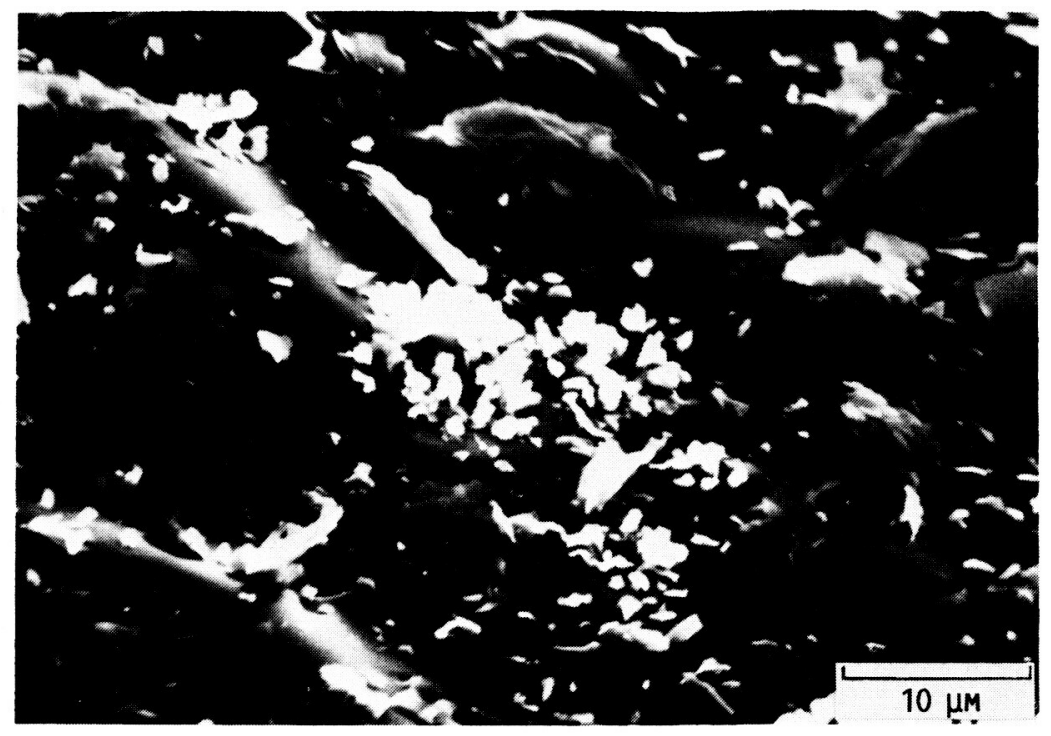

Figure 11. - Micrograph of the same surface as that of Figure 10, but at A HIGHER MAGNIFICATION AND AT A HIGHER ANGLE OF TILT $\left(60^{\circ}\right)$. THE EXTENT OF OXIDATION OF THE SILVER IS MORE EASILY SEEN.

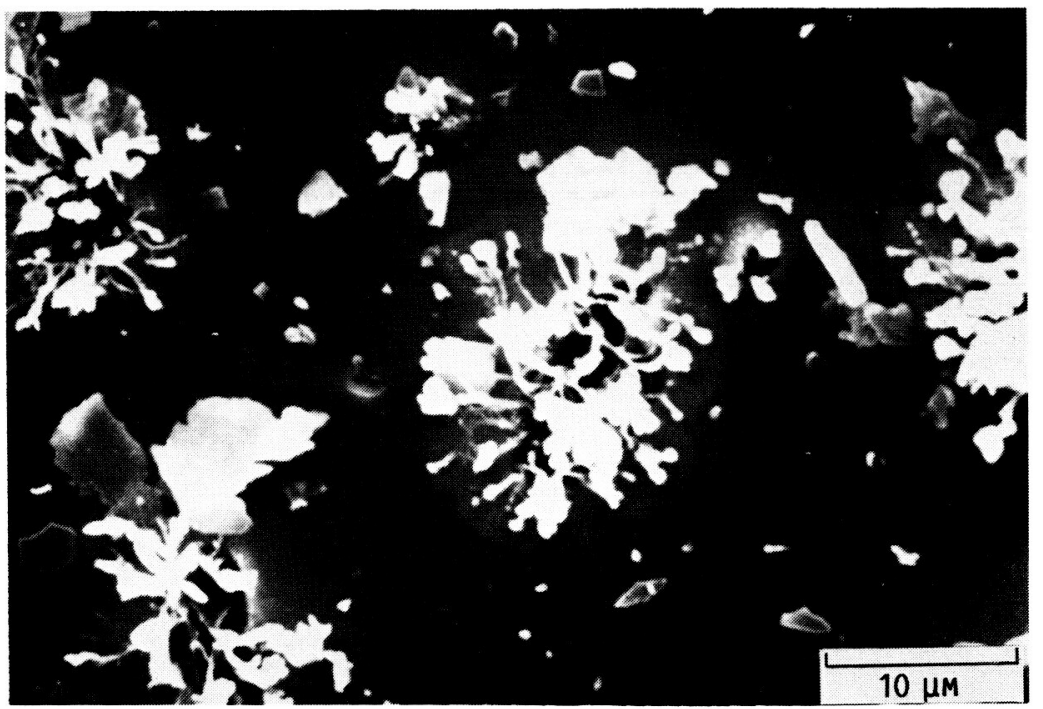

FigURE 12. - MicROGRAPH OF THE ERODED SURFACE OF SAMPLE IDENTICAL TO TO THAT OF FIGURE 10 AFTER 240 HOURS OF PLASMA ASHER EXPOSURE. SILVER OXIDE PROTRUDING THROUGH THE DEFECT SITES IS CLEARLY SEEN. IN ADDITION, TRANSVERSE OXIDATION OF THE SILVER LAYER BENEATH THE PROTECTIVE COATING IS SEEN AS A LIGHTER BORDER SURROUNDING THE DEFECT SITES. 


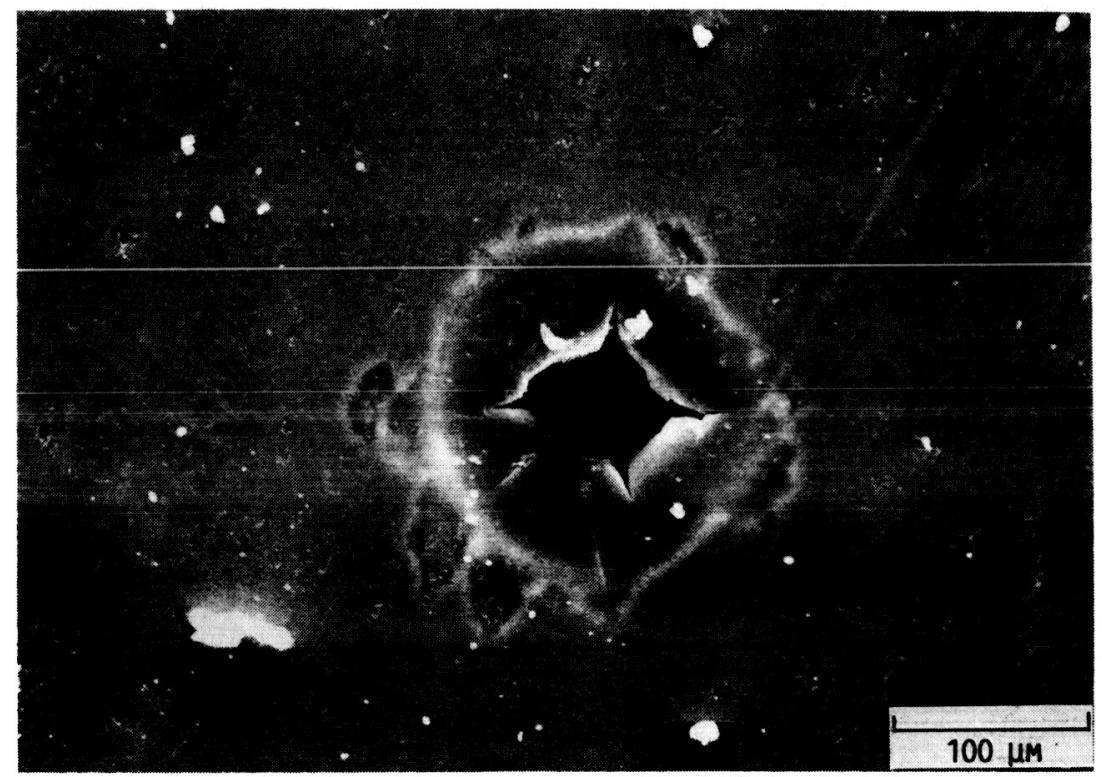

Figure 13. - Micrograph OF AN ALUMINUM REFLECTOR AFTER 270 HOURS OF Plasma asher exposure. THE PROtective coating Was MgF 2 and the SUBSTRATE WAS GRAPHITE-EPOXY. THE DEFECT SHOWN WAS NOT INTENTIONALLY INDUCED, BUT WAS CREATED DURING THE FABRICATION OR HANDLING OF THE SAMPLE. OXIDATIVE UNDERCUTTING HAS OCCURRED. 


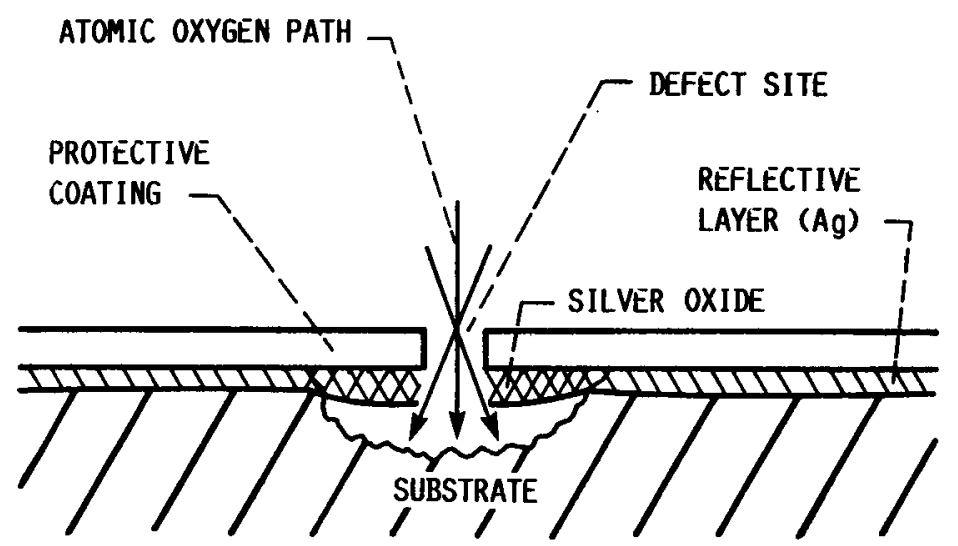

(A) OXIDATIVE UNDERCUTTING.

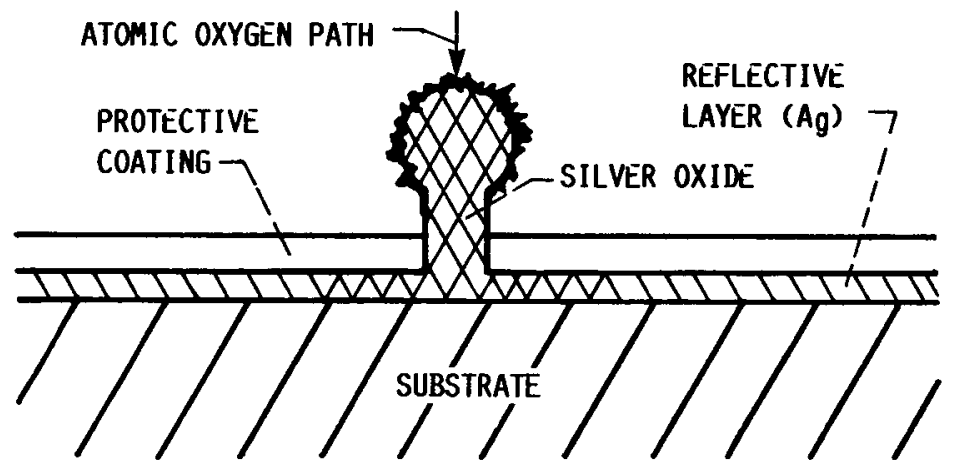

(B) TRANSVERSE OXIDATION.

FIGURE 14.- SCHEMATIC REPRESENTATION (A) OF OXIDATIVE UNDERCUTTING OF BOTH THE REFLECTIVE LAYER AND SUBSTRATE WHEN THE SUBSTRATE ITSELF IS SUSCEPTIBLE TO OXIDATION AND (B) OF TRANSVERSE OXIDATION OF THE REFLECTIVE LAYER ALONE WHEN THE SUBSTRATE IS RESISTANT TO OXIDATION. 


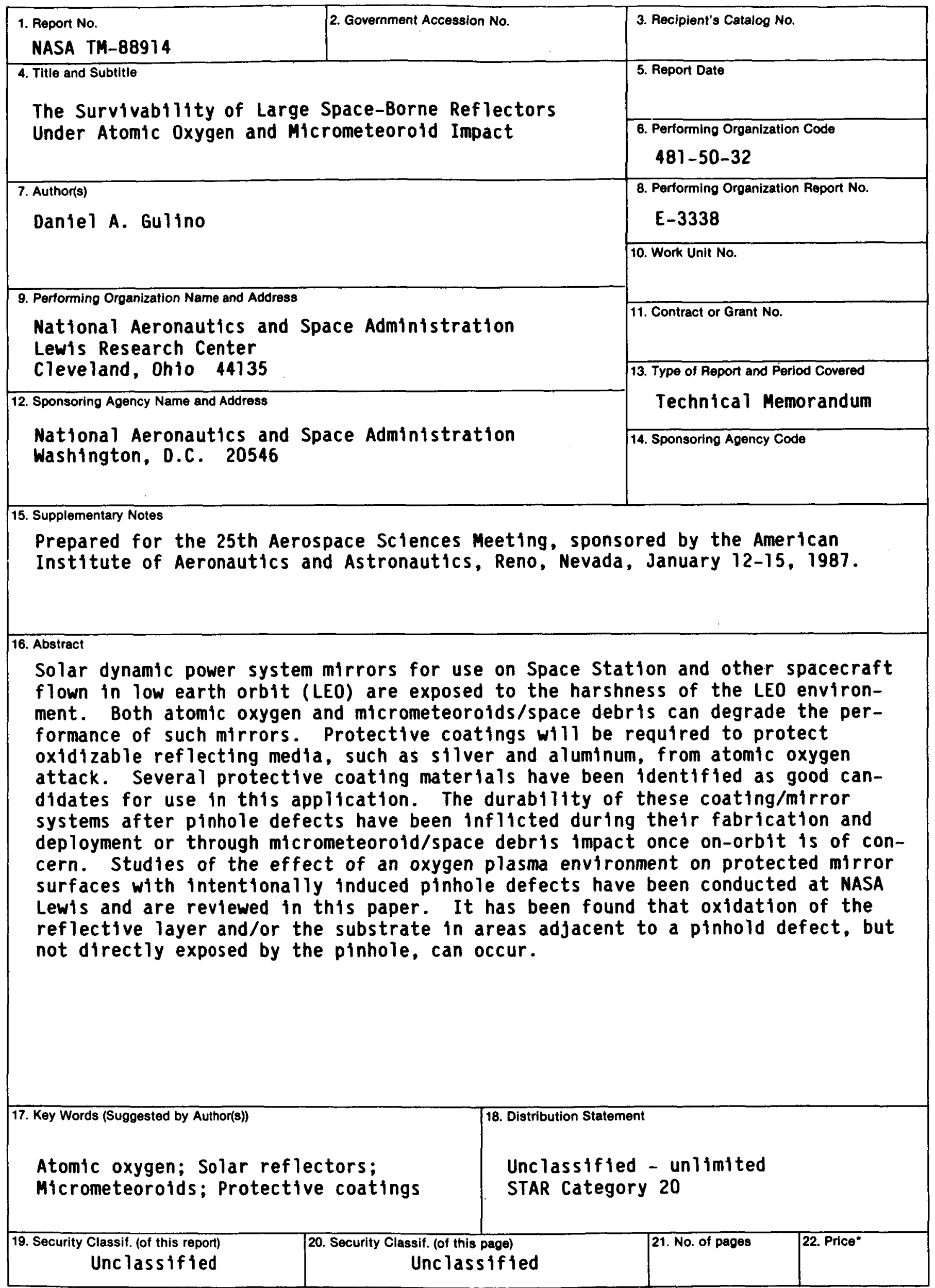

"For sale by the National Technical Information Service, Springfield, Virginia 22161 